\title{
Ionic Transport and Speciation of Lithium Salts in Glymes: Experimental and Theoretical Results for Electrolytes of Interest for Lithium-Air Batteries
}

\author{
Gabriela Horwitz, ${ }^{\dagger, \ddagger}$ Matías Factorovich, ${ }^{\dagger}$ Javier Rodriguez, $^{\ddagger, \S, \|}$ Daniel Laria, ${ }^{*}, \dagger, \S$
}

and Horacio R. Corti ${ }^{*},+,, \delta_{\infty}$

${ }^{\dagger}$ Instituto de Química Física de los Materiales, Medio Ambiente y Energía (INQUIMAE-CONICET), Facultad de Ciencias Exactas y Naturales, Universidad de Buenos Aires, Pabellón II, Ciudad Universitaria, 1428 Buenos Aires, Argentina

${ }^{\ddagger}$ Departamento de Física de la Materia Condensada, Comisión Nacional de Energía Atómica, Avda. General Paz 1499, 1650 San Martín, Buenos Aires, Argentina

${ }^{\S}$ Instituto de Nanociencia y Nanotecnología (INN CNEA-CONICET), 1650 Buenos Aires, Argentina

"ECyT, UNSAM, Martín de Irigoyen 3100, 1650 San Martín, Buenos Aires, Argentina

\section{Supporting Information}

ABSTRACT: Glycol ethers, or glymes, have been recognized as good candidates as solvents for lithium-air batteries because they exhibit relatively good stability in the presence of superoxide radicals. Diglyme (bis(2-methoxy-ethyl)ether), in spite of its low donor number, has been found to promote the solution mechanism for the formation of $\mathrm{Li}_{2} \mathrm{O}_{2}$ during the discharge reaction, leading to large deposits, that is, high capacities. It has been suggested that lithium salt association in these types of solvents could be responsible for this behavior. Thus, the knowledge of the speciation and transport behavior of lithium salts in these types of solvents is relevant for the optimization of the lithium-air battery performance. In this work, a comprehensive study of lithium trifluoromethanesulfonate (LiTf) and lithium bis(trifluoromethanesulfonyl)imide (LiTFSI) in 1,2-dimethoxyethane (DME) and diglyme, over a wide range of concentrations, have been performed. Consistent ion pairs and triplet ions formation constants have been obtained by resorting to well-known equations that describe the concentration dependence of the molar conductivities in highly associated electrolytes, and we found that the system LiTf/DME would be the best to promote bulky $\mathrm{Li}_{2} \mathrm{O}_{2}$ deposits. Unexpected differences are observed for the association constants of LiTf and, to a lesser extent, for LiTFSI, in DME and diglyme, whose dielectric constants are similar. Molecular dynamics (MD) simulations allowed us to rationalize these differences in terms of the competing interactions of the O-sites of the ethers and the $\mathrm{SO}_{x}$ groups of the corresponding anions with $\mathrm{Li}^{+}$ion. The limiting $\mathrm{Li}^{+}$diffusivity derived from the fractional Walden rule agrees quite well with those obtained from MD simulations, when solvent viscosity is conveniently rescaled.

\section{INTRODUCTION}

Theoretically, lithium-air batteries (LABs) would have a far higher energy density than any conventional battery system available. ${ }^{1,2}$ One of the main barriers for developing a commercially available LAB lies in the choice of the electrolyte, as this has to meet certain requirements, including low volatility, low viscosity, high ionic conductivity, and high chemical and electrochemical stability. ${ }^{3}$ Low viscosity will ensure high ionic and oxygen transport but, as Angell and coworkers ${ }^{4}$ quoted, all nonaqueous solvents that combine the desired low volatility with high salt dissociation power (high dielectric constant or high Lewis basicity) are always rather viscous. This is due to the unfortunate correlation between fluidity and volatility, as predicted by Eyring's theory of viscosity, which holds for a wide selection of solvents.

The electrolytes employed in Li-ion batteries, based on alkyl carbonates, were initially tested for LAB. ${ }^{5-7}$ However, experimental and theoretical studies have shown that the main cathodic discharge product was not $\mathrm{Li}_{2} \mathrm{O}_{2}$ but a number of lithium insoluble salts derived from the nucleophilic attack of the superoxide radicals, $\mathrm{O}_{2}{ }^{-}$, on the carbonates. ${ }^{8-10}$ Abraham and co-workers ${ }^{11}$ emphasized the role of the solvent donor number $(\mathrm{DN})$ on the stability of the $\mathrm{Li}^{+}-\mathrm{O}_{2}{ }^{-}$ion pair

Received: June 25, 2018

Accepted: September 3, 2018

Published: September 14, 2018 
by studying the solvents dimethyl sulfoxide (DMSO), acetonitrile $(\mathrm{ACN})$, and the glymes dimethoxyethane (DME) and tetraethylene glycol dimethyl ether (TEGDME).

This effect was further investigated by Bruce and coworkers $^{12}$ by comparing the solvents DMSO, ACN, DME, and 1-methylimidazole (Me-Im). They concluded that low-DN solvents are likely to lead to premature cell death, whereas high-DN solvents, like Me-Im and DMSO, can support higher capacities and can better sustain battery discharges. Although $\mathrm{DMSO} / \mathrm{LiClO}_{4}$ exhibit good discharge/charge for 100 cycles when a nanoporous gold cathode is used in place of a carbonbased one, ${ }^{13}$ several studies have indicated that DMSO is chemically unstable in the presence of $\mathrm{Li}_{2} \mathrm{O}_{2}$, and attempts to reproduce the cyclability of LABs employing DMSO-based electrolytes have failed. ${ }^{14-16}$

The recent interest in glymes as electrolytes for $\mathrm{LAB}$ is based on their relatively low volatility and the fact that the main discharge product is $\mathrm{Li}_{2} \mathrm{O}_{2} \cdot{ }^{10,17,18}$ Freuenberger et al. ${ }^{17}$ proposed that glymes suffer $\mathrm{O}_{2}{ }^{-}$-induced decomposition during discharge, whereas Bryantsev et al. ${ }^{19}$ have shown that monoglyme (DME) is stable against $\mathrm{O}_{2}^{-}$attack. These contradictory results on the stability of the glyme under LAB discharge conditions led to Schwenke et al. ${ }^{20}$ to perform stability studies on glymes of various chain lengths, using $\mathrm{K}_{2} \mathrm{O}$ as a superoxide radical source. They demonstrated that mono-, di-, tri-, and tetra-glyme $\left(\mathrm{CH}_{3}-\mathrm{O}-\left(\mathrm{CH}_{2}-\mathrm{CH}_{2}-\mathrm{O}\right)_{n}-\mathrm{CH}_{3}\right.$, with $n=1-4)$ are sufficiently stable against superoxide attack if they are pure enough. It has also been shown that equimolar mixtures of tri- or tetraglyme with lithium salts has ionic-liquidlike characteristics at room temperature, but there are no reports of their use in LABs. ${ }^{21} \mathrm{Du}$ et al. ${ }^{22}$ have observed that $\mathrm{LiPF}_{6}$ decomposes in tri(ethylene glycol)-substituted trimethylsilane, but it is stable in TEGDME.

The mechanism of formation of $\mathrm{Li}_{2} \mathrm{O}_{2}$ in the $\mathrm{LAB}$ cathode determines its thickness and morphology and, because it is a band gap insulator and insoluble in aprotic solvents, this has a crucial influence on the capacity of the battery. According to Bruce and co-workers, ${ }^{12}$ there are two pathways for the $\mathrm{Li}_{2} \mathrm{O}_{2}$ formation during the oxygen reduction reaction (ORR) in a LAB. The surface mechanism involves two successive oneelectron reductions leading to the formation of lithium superoxide $\left(\mathrm{Li}_{2} \mathrm{O}\right)$ intermediary, which finally converts to $\mathrm{Li}_{2} \mathrm{O}_{2}$ on the surface. The solution mechanism consist of the formation of the superoxide ion $\left(\mathrm{O}_{2}{ }^{-}\right)$, which forms ion pairs and higher aggregates with $\mathrm{Li}^{+}$ions in the solution, which diffuse before chemical disproportion into $\mathrm{Li}_{2} \mathrm{O}_{2}$. Thus, the solution mechanism prompts the formation of a thick layer of $\mathrm{Li}_{2} \mathrm{O}_{2}$, without the limitations of the electrochemical surface pathway, due to the insulating nature of the deposit that selflimits its growth.

Solvents with high $\mathrm{DN}$ promote the solution mechanism by reducing the Lewis acidity of the $\mathrm{Li}^{+}$ion and helping to increase the stability of the superoxide ion, promoting large $\mathrm{Li}_{2} \mathrm{O}_{2}$ deposits; on the other hand, solvents with low DN promote the surface mechanism, leading to thin films (5-10 $\mathrm{nm}$ in thickness). ${ }^{12}$

Recently, Aurbach and co-workers ${ }^{23}$ found a strong correlation between the dissociation degree of the $\mathrm{Li}^{+}$ion and the ORR behavior, even more important than the $\mathrm{DN}$ one, when diglyme is used as a solvent. They concluded that a "bottom-up" $\mathrm{Li}_{2} \mathrm{O}_{2}$ precipitation mechanism operates with highly dissociated Li salts (such as LiTFSI) in the low-DN diglyme where the $\mathrm{Li}^{+}$ion, weakly coordinated to the counteranion, will associate to a superoxide to form unstable $\mathrm{LiO}_{2}$, which, in turn, converts into $\mathrm{Li}_{2} \mathrm{O}_{2}$ by chemical disproportionation, or electrochemically via the transfer of a second electron. These processes take place near the cathode, leading to a full coverage of its surface with $\mathrm{Li}_{2} \mathrm{O}_{2}$. Once a few peroxide layers are formed, the electrons cannot penetrate further and the discharge process stops.

A “top-down" $\mathrm{Li}_{2} \mathrm{O}_{2}$ precipitation mechanism occurs with highly associated salts ( such as $\mathrm{LiNO}_{3}$ ) in diglyme. In this case, the $\mathrm{Li}^{+}$ion, strongly coordinated to its counteranion, is less acidic and exhibits a reduced affinity toward the metastable superoxide anion, which is now able to move away from the cathode surface before being associated to $\mathrm{a} \mathrm{Li}^{+}$ion to form $\mathrm{LiO}_{2}$, which then disproportionates into $\mathrm{Li}_{2} \mathrm{O}_{2}$. Through this mechanism, the $\mathrm{Li}_{2} \mathrm{O}_{2}$ growth can expand in all directions. The higher the strength of the ionic association of the $\mathrm{Li}^{+}$ions with the counteranion, the longer the superoxide is stabilized and can diffuse far from the cathode surface without forming $\mathrm{LiO}_{2} \cdot{ }^{23}$ These results are consistent with those reported by Burke et al., ${ }^{24}$ who found a higher LAB discharge capacity using a mixture of $\mathrm{LiNO}_{3}$ and LiTFSI, dissolved in DME, with a high $\mathrm{NO}_{3}^{-} / \mathrm{TFSI}^{-}$ratio.

These observations have triggered the interest in the study of the ion association of lithium salts in solvents relevant for $\mathrm{LABs}$ in the quest for identifying the best descriptors for solvent stability and discharge capacity in nonaqueous LABs. ${ }^{25}$ The experimental criteria commonly adopted for estimating the relative association degree of LABs electrolytes in promoting the top-down $\mathrm{Li}_{2} \mathrm{O}_{2}$ deposition mechanism is based on the comparison of the specific conductivity in concentrated solutions, ${ }^{23}$ which could lead to contradictory results, as we will demonstrate in this work.

Here, we report precise measurements of the ionic conductivity of two lithium salts (LiTf and LTFSI) in the glymes 1,2-dimethoxyethane (DME) and bis(2-methoxyethyl)ether (diglyme) (Figure 1) over a wide range of

Lithium trifluoromethanesulfonate
(Lithium triflate, LiTf)

Figure 1. Structure of the lithium salts and glymes studied in this work.

concentrations, which allowed us to obtain reliable values of transport parameters, along with the ion pairs and triplet ions formation constants, in these electrolyte systems of relevance for LAB. These experimental measurements were complemented with microscopic interpretations of the differences in the dynamic and association parameters provided from molecular dynamics (MD) simulations of the four systems, yielding a comprehensive picture of the factors that determine the ionic mobilities and ionic association in these lowdielectric-constant solvents.

\section{RESULTS AND DISCUSSION}

This section is organized as follows: first, the results of the molar electrical conductivity of the four systems studied are reported and analyzed; second, the speciation calculated from 

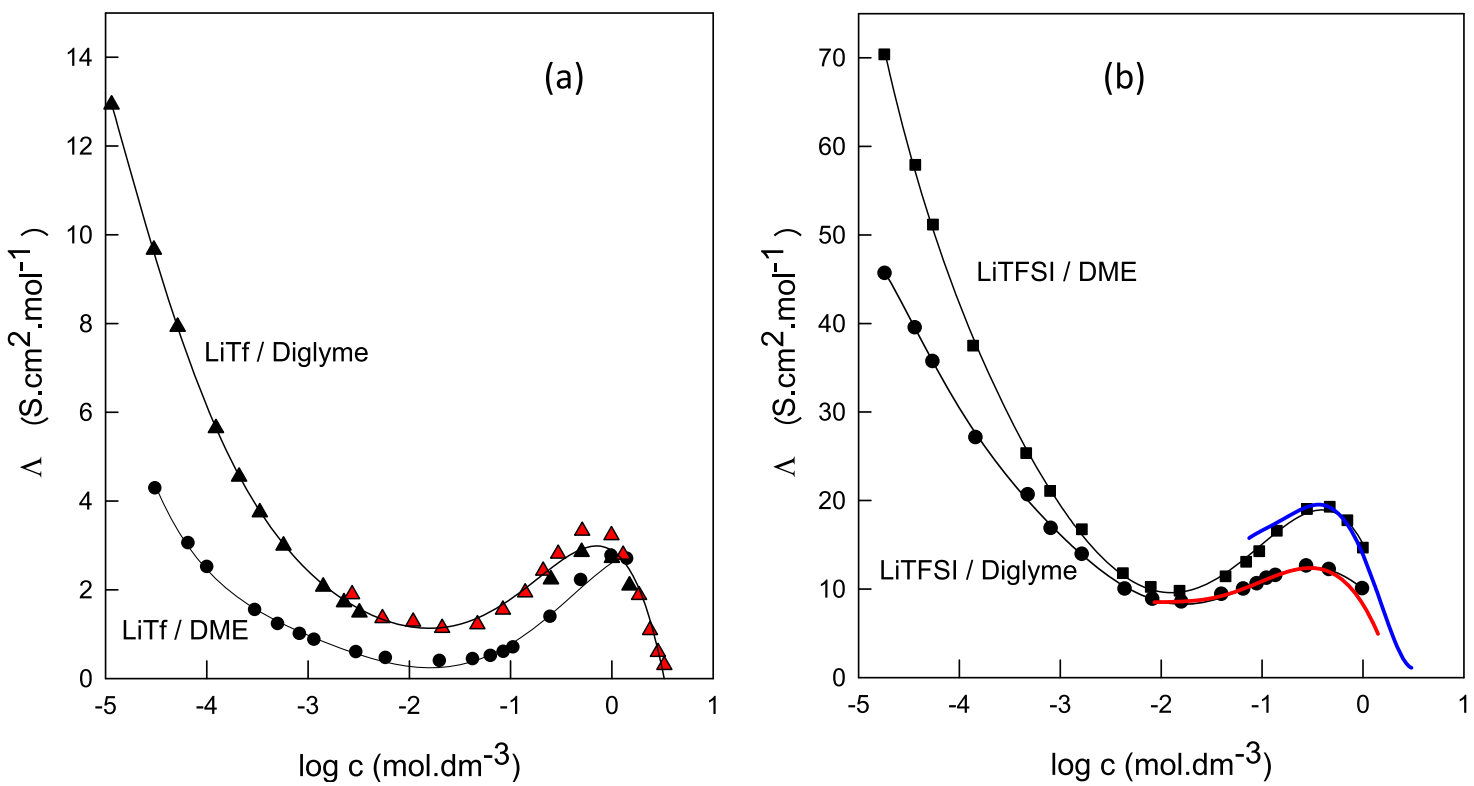

Figure 2. Molar conductivity of (a) LiTf and (b) LiTFSI in DME and diglyme at $298.15 \mathrm{~K}$, along with the data by Petrowsky et al. ${ }^{26}$ (red triangle up solid) for the system LiTf/diglyme $(2.72 \mathrm{mM}<c<3.3 \mathrm{M})$, by Brouillette et al. ${ }^{27}$ (red and blue lines) for LiTFSI/DME $(0.074 \mathrm{M}<c<2.8 \mathrm{M})$, and LiTFSI/diglyme $(0.0085 \mathrm{M}<c<1.4 \mathrm{M})$.

the measured molar conductivity using different conductivity models is discussed; next, we present a microscopic insight into the speciation in these systems on the basis of the MD simulations. Finally, we analyze the main features of the ionic diffusion in glymes by comparing the experimental diffusion coefficients, derived from the conductivity data, with the MD simulations.

2.1. Molar Conductivities of Lithium Salts in Glymes as a Function of Concentration. The conductivity measurements were carried out over a wide range of concentrations ranging from $(1-3) \times 10^{-5} \mathrm{M}$ up to $1.0 \mathrm{M}$ for LiTFSI and up to $1.5 \mathrm{M}$ for LiTf in both glymes. Table S1 in the Supporting Information summarizes the results obtained for the four system studied, whereas Figure 2a,b illustrate the concentration dependence of the molar conductivity.

In Figure 2a,b are also plotted the conductivity data reported by Petrowsky et al. ${ }^{26}$ for the system LiTf/diglyme and Brouillette et al. $^{27}$ for the LiTFSI/DME and the LiTFSI/ diglyme systems. The concentration range of LiTFSI reported by Brouillette et al. ${ }^{27}$ in both glymes does not cover the diluted region, which is necessary to obtain information on the association constants. The same observation applies to the Petrowsky et al. $^{26}$ data for the system LiTf/diglyme, but, as we will discuss in what follows, the association constants reported in that study were obtained using a different approach from the one adopted here.

The general form of the conductivity vs concentration curve is typical of a strongly associated electrolyte, where the molar conductivity reaches values much lower than the infinite dilution upper value, even at very low concentrations, due to the high value of the ion-pair association constant, $K_{\mathrm{A}}$ corresponding to the equilibrium:

$$
\mathrm{Li}^{+}(\sin )+\mathrm{X}^{-}(\sin ) \leftrightarrow \operatorname{LiX}(\sin )\left(K_{\mathrm{A}}\right)
$$

In strongly associated electrolytes, the reduction of the conductivity due to the formation of neutral ion pairs is more important that the decreasing of ionic mobility due to the ion-ion interactions described by the Onsager limiting law or the extended theories valid up to higher concentrations. As the salt concentration increases, the formation of triplet ions becomes relevant, operated via the following processes:

$$
\begin{aligned}
& \mathrm{Li}^{+}(\operatorname{sln})+\mathrm{LiX}(\operatorname{sln}) \leftrightarrow \mathrm{Li}_{2} \mathrm{X}^{+}(\operatorname{sln}) \text { or } \\
& \mathrm{X}^{-}(\operatorname{sln})+\mathrm{LiX}(\operatorname{sln}) \leftrightarrow \mathrm{LiX}_{2}^{-}(\operatorname{sln}) \quad\left(K_{\mathrm{T}}\right)
\end{aligned}
$$

Thus, the population of charged triplets increases, whereas that of ion pairs decreases, leading to a minimum in the conductivity vs concentration curve. The observed maximum in the curve as the concentration is further increased partially obeys the formation of larger aggregates (as ion quadruplets) and also the decrease of ionic mobilities due to the increasing viscosity of the media at very high concentrations, reducing the molar conductivity.

It can be observed that the minimum in molar conductivities occurs at concentrations around $0.02 \mathrm{M}$ for all the electrolytes, whereas the maximum in the concentrated region lies around 1 $\mathrm{M}$ for LiTf/DME, $0.5 \mathrm{M}$ for LiTf/diglyme and LiTFSI/DME, and $0.3 \mathrm{M}$ for LiTFSI/diglyme. The minimum conductivity concentration is related to the constant $K_{\mathrm{T}}{ }^{28}$ suggesting that the value of this parameter would be similar for the $\mathrm{Li}$ salts measured in this work, and also for the $\mathrm{LiBF}_{4} / \mathrm{DME}$ system measured by Barthel et al., ${ }^{29}$ which exhibits a minimum molar conductivity at $0.021 \mathrm{M}$ at $298 \mathrm{~K}$.

2.2. Speciation of Lithium Salts in DME and Diglyme from Conductivity Data. Ionic association is expected to dominate the concentration dependence of lithium salts conductance in DME and diglyme considering the low dielectric constant of these solvents (see Table S2). The cluster theory of electrolytes, ${ }^{30}$ an extension of the Bjerrum model of ion pairing, considers that the critical parameter that determines the degree of ion association of an electrolyte is the reduced temperature

$$
T^{*}=\frac{k T \varepsilon \sigma}{(z e)^{2}}
$$


Table 1. Infinite-Dilution Conductivity and Ion Association Constants Determined Using the FK and the FHFP Treatments

\begin{tabular}{llll}
\multicolumn{1}{c}{ system } & \multicolumn{1}{c}{ LiTf/DG } & \multicolumn{1}{c}{ LiTf/DME } & \multicolumn{1}{c}{ LiTFSI/DG } \\
$\Lambda^{0}\left(\mathrm{~S} \mathrm{~cm}^{2} \mathrm{~mol}^{-1}\right)$ & $60 \pm 3$ & $129 \pm 9$ & $54 \pm 3.5$ \\
molarity range-FK & $2 \times 10^{-4}$ to 0.042 & $3 \times 10^{-5}$ to 0.06 & $3 \times 10^{-5}$ to 0.015 \\
$K_{\mathrm{A}}\left(\mathrm{dm}^{3} \mathrm{~mol}^{-1}\right)-\mathrm{FK}$ & $(9 \pm 2) \times 10^{5}$ & $(2.7 \pm 0.4) \times 10^{7}$ & $(1.5 \pm 0.4) \times 10^{4}$ \\
$K_{\mathrm{T}}\left(\mathrm{dm}^{3} \mathrm{~mol}^{-1}\right)-\mathrm{FK}$ & $80 \pm 15$ & $68 \pm 6$ & $(5 \pm 2) \times 10^{4}$ \\
molarity range-FHFP & $3 \times 10^{-5}$ to 0.001 & $3 \times 10^{-5}$ to 0.006 & $130 \pm 50$ \\
$K_{\mathrm{A}}\left(\mathrm{dm}^{3} \mathrm{~mol}^{-1}\right)-$ FHFP & $(11 \pm 2) \times 10^{5}$ & $(2.8 \pm 0.5) \times 10^{7}$ & $1 \times 10^{-5}$ to 0.003 \\
\hline
\end{tabular}

where $z e$ is the ionic charge (we consider symmetric electrolytes with $\left.z_{+}=\left|z_{-}\right|=z\right), k$ is the Boltzmann's constant, $T$ is the temperature, $\varepsilon$ is the solvent relative dielectric constant, and $\sigma=r_{+}+r_{-}$is the mean ionic diameter.

For LiTf and LiTFSI in DME and diglyme at $298.15 \mathrm{~K}, \mathrm{~T}^{*}$ ranges between 0.046 and 0.067 using the crystal ionic radius calculated according to the method proposed by Okan and Champeney ${ }^{31}$ (0.090, 0.307, and $0.450 \mathrm{~nm}$ for $\mathrm{Li}^{+}, \mathrm{Tf}^{-}$, and $\mathrm{TFSI}^{-}$, respectively). This reduced temperature is quite low and leads us to predict that the speciation in such electrolytes should be influenced by the formation of ion pairs, triplet ions, or even higher ion clusters at the high lithium concentration regime used in lithium batteries, as it was effectively reported in several cases. ${ }^{26,27,29}$

The association constants $K_{\mathrm{A}}$ and $K_{\mathrm{T}}$ can be obtained from the concentration dependence of the molar conductivities by resorting to the well-known equations developed by Fuoss and Kraus (FK), ${ }^{32}$ Fuoss-Hsia-Fernández-Prini (FHFP), ${ }^{33,34}$ and Salomon and Uchiyama, ${ }^{35}$ which are discussed in the Supporting Information. In all the cases, the distance of the closest approach of ions, $d$, needs to be known, along with the limiting molar conductivity of the salt, $\Lambda^{0}$, and that of the triple ions, $\Lambda_{3}^{0}$, to obtain $K_{\mathrm{A}}$ and $K_{\mathrm{T}}$. In strongly associated electrolytes, like those studied in this work, the molar conductivity of the most diluted solution is too far from $\Lambda^{0}$, even for the solution with concentrations close to $10^{-5} \mathrm{~mol}$ $\mathrm{dm}^{-3}$. Therefore, $\Lambda^{0}$ cannot be obtained by extrapolating the conductivity data at infinite dilution. In the Supporting Information, we describe in detail the procedure used to obtain $\Lambda^{0}$, which is based on the use of the fractional Walden rule $^{36}$ (eq S14 in the Supporting Information), whereas the limiting molar conductivity of the triple ions is approached by $\Lambda_{3}^{0}=2 \Lambda^{0} / 3$. $^{37}$ The infinite-dilution conductivities of $\mathrm{Li}^{+}$, $\mathrm{Tf}^{-}$, and $\mathrm{TFSI}^{-}$in both solvents at $298.15 \mathrm{~K}$ are summarized in Table S4. The infinite-dilution conductivities of LiTf and LiTFSI in both solvents were calculated from the ionic contributions by resorting to Kohlrausch's law (eq S15 in the Supporting Information).

To determine the speciation of lithium salts in DME and diglyme from the conductivity data reported in Table S1, we used the FK and FHFP equations (eqs S8 and S1). The best-fit association constants obtained for the studied systems are summarized in Table 1, where we include the range of concentrations used in the data fit procedure.

The ion-pair association constant of the studied systems are plotted in Figure 3 as a function of the inverse of the solvent dielectric constant, along with the data reported in literature in other solvents over a wide range of dielectric constants (see Table S4 in the Supporting Information).

Figure 3 includes the results for $\mathrm{LiAsF}_{6}$ and $\mathrm{LiBF}_{4}$, which have been studied in several solvents with $\varepsilon<10$. As expected, from the simple Bjerrum's ion association theory, $\log K_{\mathrm{A}}$ varies linearly with $\varepsilon^{-1}$ for $\mathrm{LiAsF}_{6}$ and $\mathrm{LiBF}_{4}$. That behavior is not so

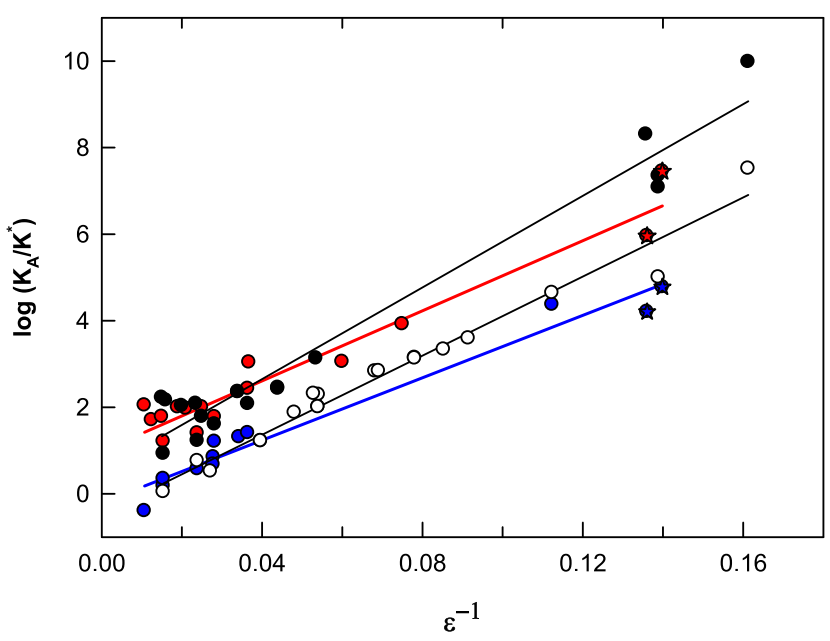

Figure 3. Ion-pair formation constant of several $\mathrm{Li}$ salts as a function of the inverse of the solvent dielectric constant: LiTFSI (blue circle solid); LiTf (red circle solid); $\operatorname{LiAsF}_{6}(O)$; and $\operatorname{LiBF}_{4}(\mathbf{O})$. The stars represent the data measured in this work.

clear for LiTf and LiTFSI due to the lack of information on ion association in solvents with low dielectric constant $(\varepsilon<10)$. In fact, a very large difference is observed for $K_{\mathrm{A}}$ in the case of LiTf in DME and diglyme (see Table 2), although they have

Table 2. Experimental and Calculated Gibbs Free Energy Changes for the Association Process at 298.15 K

\begin{tabular}{lcc}
\multicolumn{1}{c}{ system } & $\Delta G_{\text {assoc }}(\exp ) / k T$ & $\Delta G_{\text {assoc }}($ calc $) / k T$ \\
LiTf/DG & $-13 \pm 3$ & -23.8 \\
LiTf/DME & $-17 \pm 2$ & -29.7 \\
LiTFSI/DG & $-9 \pm 2$ & -12.5 \\
LiTFSI/DME & $-11 \pm 4$ & -13.4 \\
\hline
\end{tabular}

almost identical dielectric constants. Although the differences are not as large as in the case of LiTf, a similar trend is observed for LiTFSI in those solvents.

Therefore, it seems that a simple electrostatic model of ion association is unable to explain the behavior of the studied systems. We will advance in the discussion of this behavior in Section 2.3.

It is possible to explain the conductivity trends observed all over the wide range of concentrations studied by resorting to the salt speciation and solvent viscosity. At infinity dilution, where the salts are fully dissociated, the ionic conductivities follow Walden's rule, that is, the ionic conductivity is proportional to the inverse of the product of the ion radius times the solvent viscosity. Thus, the conductivities of the three ions in DME are almost double the corresponding values in diglyme because the viscosity of this solvent is double that of DME. On the other hand, in both solvents, the conductivity of the smaller $\mathrm{Tf}^{-}$ion is larger than that of the bulkier $\mathrm{TFSI}^{-}$ion. 
At this limiting concentration, the expected order of conductivities is LiTf/DME > LiTFSI/DME > LiTf/DG > LiTFSI/DG, in agreement with the results reported in Table 1.

However, Figure 2a,b shows that even at concentrations as low as $10^{-5} \mathrm{M}$, the conductivity order changes to LiTFSI/ DME > LiTFSI/DG > LiTf/DG > LiTf/DME. This order can be explained by resorting to the speciation summarized in Table 2, which reveals that the system LiTf/DME is by far more associated than the others, so it becomes the less conducting of the four systems over the whole concentration range. It is also observed that the conductivity of LiTf in DME is lower than that in diglyme, but the opposite occurs for LiTFSI. This behavior can be rationalized by considering the opposite effects of increasing ionic association and solvent fluidity (decreasing viscosity). The difference in ion-pair association of LiTf between DME and diglyme (as determined by $K_{\mathrm{A}}$ ) overpasses the differences of viscosities, whereas in the case of LiTFSI, the differences in the ion-pair association in both solvents are not so large and the differences in viscosities determine the conductivity order. In Section 2.3, we will analyze the molecular interpretation of the speciation differences in the four systems.

It is also interesting to compare our results of speciation and conductivity in the system LiTf/diglyme and LiTf/DME with those reported in literature. Petrowsky et al. ${ }^{26}$ have calculated the ionic speciation of the LiTf/diglyme system by resorting to IR spectroscopy. They observed three IR bands assigned to (i) free $\mathrm{Tf}^{-}$anion, (ii) $\mathrm{Li}^{+} \mathrm{Tf}^{-}$ion pairs + triple anion $\left(\mathrm{LiTf}_{2}{ }^{-}\right)$, and (iii) LiTf dimer + triple cation $\left(\mathrm{Li}_{2} \mathrm{Tf}^{+}\right)$. However, it was arbitrarily assumed that triple ions are absent, and the bands were assigned to free ions, ion pairs, and dimers $\left(\mathrm{Li}_{2} \mathrm{Tf}_{2}\right)$; that is, the speciation is thought to be determined by the ion-pair process $\left(K_{\mathrm{A}}\right)$ and dimers' formation (2LiTf $\leftrightarrow \mathrm{Li}_{2} \mathrm{Tf}_{2}$ ), characterized by the equilibrium constant $K_{\mathrm{D}}$. Both constants were calculated as a function of concentration, using the species relative concentrations derived from the IR spectra, and the molar conductivity was calculated with the concentration of free ions, $c_{\mathrm{f}}$, at each salt concentration, $c$

$$
\Lambda=\frac{c_{\mathrm{f}}}{c} F\left(u_{\mathrm{Li}^{+}}+u_{\mathrm{Tf}^{-}}\right)
$$

where $u_{\mathrm{i}}$ are the ionic mobilities $\left(\lambda_{\mathrm{i}}=F u_{\mathrm{i}}\right)$. By fitting the sum of $\mathrm{Li}^{+}$and $\mathrm{Tf}^{-}$ions mobilities to the experimental molar conductivity, Petrowsky et al. ${ }^{26}$ concluded that the concentration dependence of the molar conductivity is to a major extent due to the variation in ion mobilities with concentration. Surprisingly, for concentrations lower than $0.5 \mathrm{M}$, the sum of the ionic mobilities increases with increasing salt concentration, in contradiction with the expected behavior, taking into account the existence of ion-ion interactions and the increment in the solution viscosity, which is expected to slow down ionic mobility. This unexpected behavior is due, without doubt, to the scheme of ionic association proposed by Petrowsky et al., ${ }^{26}$ which derives from an arbitrary choice of the predominant species instead of resorting to conductivity models, like those used in this work, that are based on a reasonable physical behavior of ionic mobilities with concentration.

Claude-Montigny et al. ${ }^{38}$ have calculated the speciation in LiTf/diglyme at temperatures between 253 and $343 \mathrm{~K}$ by a direct fitting of the conductivity data in the concentration range $10^{-6}-10^{-3} \mathrm{M}$, considering the formation ion pairs and triple ions and assuming the validity of the Walden rule. Even when they neglected the ion-ion interactions effects at the concentrations used in the calculation, their results at $298 \mathrm{~K}$ yield $K_{\mathrm{A}}=(4.0 \pm 0.5) \times 10^{5}$, which compares reasonably well with the one obtained in this work (see Table 1). This is due to a compensation of errors because they estimated a much lower $\Lambda^{0}$ of LiTf in diglyme than that calculated in this work and, as we will demonstrate in a forthcoming work, the Walden rule is not obeyed in these low-dielectric-constant solvents exhibiting a strong ion association.

Siekierski and co-workers ${ }^{39,40}$ determined the association constant of LiTf in DME and diglyme from the conductivity data of ${ }^{7} \mathrm{Li}$ and ${ }^{19} \mathrm{~F}$ NMR chemical shift analysis. Unfortunately, neither the temperature of the experiments nor the $\Lambda^{0}$ used for the FK treatment was indicated. The molar conductivities reported by the authors for the LiTf/DME system are considerably higher than those depicted in Figure 2a and, consequently, the reported association constant is 4 orders of magnitude lower than that found in our study. The values of $K_{\mathrm{A}}$ reported for LiTf in DME and diglyme are completely different, depending on whether they were obtained from ${ }^{19} \mathrm{~F}$ $\operatorname{NMR}\left(\approx 1.6 \times 10^{4} \mathrm{dm}^{3} \mathrm{~mol}^{-1}\right)$ or ${ }^{7} \operatorname{Li} \operatorname{NMR}\left(>10^{6} \mathrm{dm}^{3} \mathrm{~mol}^{-1}\right)$. These anomalies, together with the doubts about the quality of NMR spectra at low concentrations, and the water content of the solvents make the comparison with our results irrelevant.

In summary, we conclude that the best description of the speciation of the lithium salts in glymes arises from the conductivity equations, like FK and FHFP, which account for the ion-ion interactions and the formation of ion pairs and triplet ions in the dilute and moderate-concentration regions, instead of expressions based on mostly arbitrary ionic species distributions estimated from spectroscopy data.

At this point, it will be useful to discuss the criteria adopted by Aurbauch and co-workers ${ }^{23}$ to classify the association strengths of different lithium salts in diglyme, already mentioned in Section 1, that are based on the measurement of the conductivities of the corresponding $1 \mathrm{M}$ salt solutions. The simple observation of Tables 2 and S1 seems to indicate that such a criterion is not generally applicable, except when one compares different salts in the same solvent. Thus, the specific conductivities of $1 \mathrm{M} \mathrm{LiTf}$ in diglyme and DME are practically the same, (i.e., 2.7 and $2.8 \mathrm{mS} \mathrm{cm}^{-1}$, respectively), even though the association constants differ by a factor 30; in contrast, the conductivity of $1 \mathrm{M}$ LiTFSI in DME is almost $50 \%$ higher than that of $1 \mathrm{M}$ LiTFSI in diglyme in spite of the fact that the association constant of TFSI in diglyme is a factor 3 larger than that in DME. Therefore, we conclude that the simple comparison of the specific conductivities of $1 \mathrm{M}$ electrolyte solutions does not reflect the real ionic association of the lithium salts because it does not account for the solvent viscosity effects.

From the point of view of the influence of the ion association on the extension of the discharge capacity of a $\mathrm{LAB}$, the system LiTf/DME, having an association constant 30-1800 times higher than the other three electrolytes, would be recommended to promote large (probably toroidal shape) $\mathrm{Li}_{2} \mathrm{O}_{2}$ discharge deposits through a top-down mechanism, as proposed by Aurbauch and co-workers. ${ }^{23}$

2.3. Lithium Salt Speciation from MD Simulation. At first glance, given the similarities between the dielectric characteristics of diglyme and DME, the changes in the association constants reported in Table 2-most notably, the 2 orders of magnitude difference between the LiTf results in the two solvents-are puzzling. Looking for physical interpreta- 

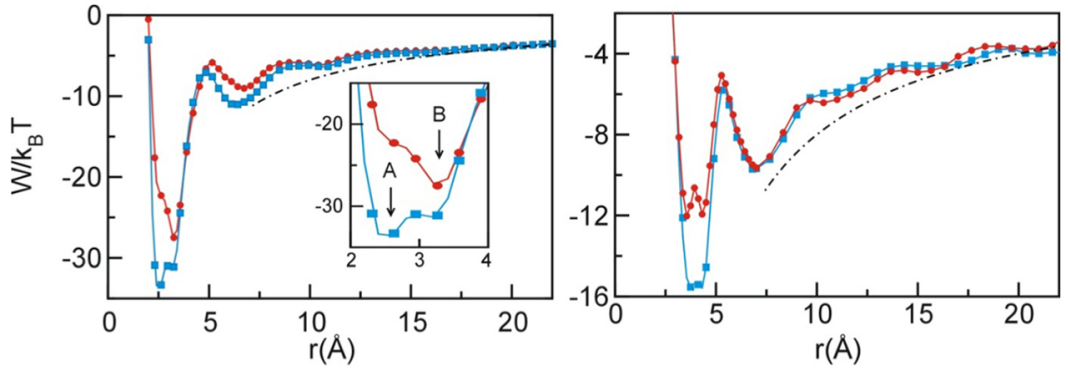

Figure 4. Potential of mean force for LiTf (left panel) and LiTFSI (right panel) in DME (blue curves) and diglyme (red curves). The dot-dashed lines represent the macroscopic screened Coulomb decay (see text).

tions of this feature, we performed a series of simulation experiments to estimate the values of $K_{\mathrm{A}}$ from an alternative microscopic perspective. The simplest and most direct route to perform such an analysis relies on the examination of the potential of mean force, $W(\xi)$, for solvated ionic species. In the present case, to do so, we resorted to the adaptive biasing force methodology, as implemented in the NAMD simulation software (see the Supporting Information for a description of the procedure) using the cation-anion distance as a reaction coordinate, i.e., $\xi=r$. The results are displayed in the two panels included in Figure 4.

The gross features of the four plots can be interpreted in terms of three distinctive behaviors: (i) at short interionic distances, the curves present deep minima (of the order 15-30 $k T)$, corresponding to strongly bounded contact-ion-pair (CIP) configurations; (ii) as one moves toward larger distances, one can also observe secondary, much shallower, minima at $r \approx 7 \AA$, which correspond to marginally stable solvent-separated-ion-pair (SSIP) configurations; (iii) finally, beyond the latter distances, the curves progressively loose structure and decay to zero following the expected, $-e^{2} /(r \varepsilon)^{-1}$, macroscopic behavior. Note that similarities in the dielectric behavior of the two solvents are clearly reflected in the practically unified decays of all the curves beyond, say, $15 \AA$.

Following previous studies, estimates for $K_{\mathrm{A}}$ can be readily obtained from ${ }^{41}$

$$
K_{\mathrm{A}}=4 \pi N_{\mathrm{A}} \int_{0}^{\xi} r^{2} \mathrm{e}^{-W(r) / k T} \mathrm{~d} r
$$

where $\xi$ represents the position of the barrier separating CIP from SSIP configurations.

Results of the equilibrium constant, expressed in terms of the Gibbs free energy changes for the association process, namely,

$$
G_{\text {assoc }}=-k T \ln \frac{K_{\mathrm{A}}}{K^{*}}
$$

where $K^{*}=1 \mathrm{dm}^{3} \mathrm{~mol}^{-1}$, and of the experimental association constants are listed in columns 2 and 3 of Table 2, respectively.

A direct inspection of the entries reveals that simulation results reproduce the association trends found experimentally, although they strongly overestimate the energetics of the associated ion pairs by several $k T$, most notably in the strongest associated cases involving LiTf. As such, we are led to conclude that the simulation predictions should be regarded only as qualitative estimators. We remark that, somehow, this drawback could have been anticipated if one takes into account previous theoretical calculations of the electronic structure of LiTf in diglyme, ${ }^{42}$ which revealed that a considerable extent of charge transfer-of the order of $0.5 e$ - occurs at contact-ionpair configurations. Consequently, any analysis based on pseudopotentials that neglect local polarization fluctuations will necessarily overestimate the interionic Coulomb attractions, yielding association constants that are too high.

Despite this drawback, the simulated profiles of $W(r)$ still might provide key elements to rationalize the differences in the degree of ionic association in the two solvents. The analysis of the LiTf curves that appear on the top panel of Figure 5 will be

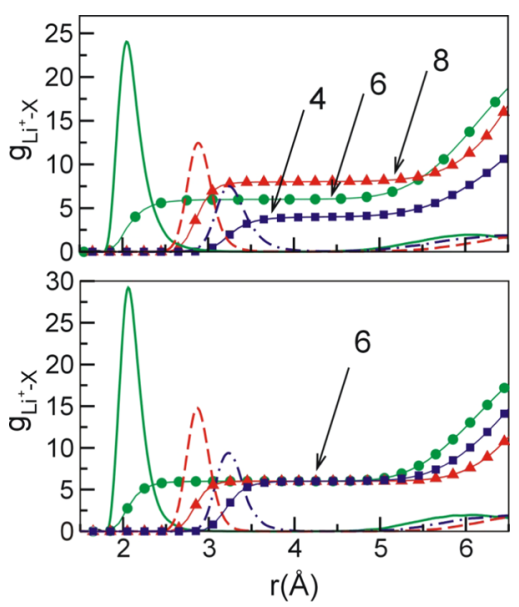

Figure 5. $\mathrm{Li}^{+}-$solvent pair correlation functions and cumulative integrals. DG (DME) results are shown in the top (bottom). O: green lines and circles; methylene $\mathrm{C}\left(-\mathrm{CH}_{2}-\right)$ : red lines and triangles, methyl $\mathrm{C}\left(-\mathrm{CH}_{3}\right)$ : blue lines and squares. The numbers indicate site populations in the first solvation shell of $\mathrm{Li}^{+}$ion.

instructive. More specifically, we will focus attention on the structures of the curves at short interionic distances that appear in the inset. In the two plots, one clearly perceives the presence of two local minima at $r=2.5$ and $3.25 \AA$ (hereafter referred to as configurations of types $\mathrm{A}$ and $\mathrm{B}$, respectively).

Before analyzing this feature, it will be useful to briefly digress on the characteristics of the solvation of isolated $\mathrm{Li}^{+}$ ions in these solvents.

An analysis based on the pair correlation functions that appear in Figure 5 reveals that, in agreement to previous Monte Carlo, ${ }^{43}$ density functional theory, ${ }^{44}$ and $\mathrm{MD}^{45-47}$ results, the solvation structures of the cation in both glymes can be cast in terms of octahedral arrangements, with six Osites tightly bound to the ion. For the longer diglyme, the closest solvation shell involves two solvent molecules, whereas for the shorter DME, the latter number moves up to three.

Interestingly, our simulations reveal that this coordination of the cation with the environment articulated via six $\mathrm{O}$-sites is 
A

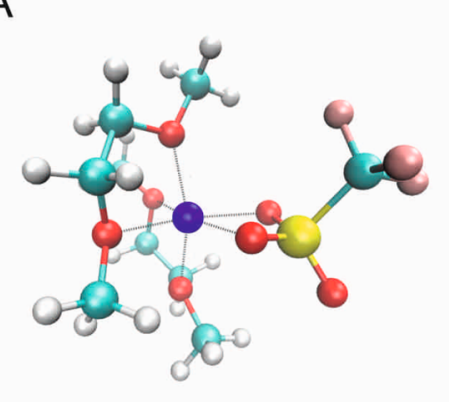

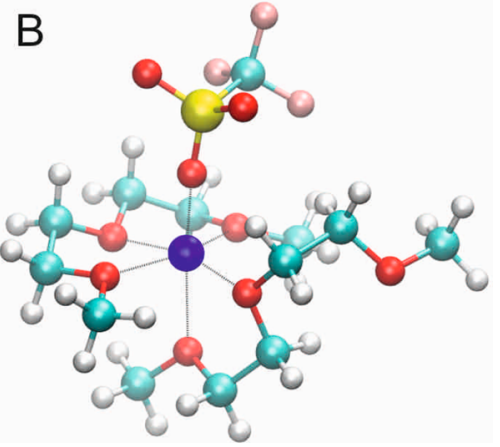

Figure 6. Snapshots for contact-ion-pair solvation structures corresponding to the local minima observed in $W(r)$ (see text). Panel (A): LiTf in DME; panel (B): LiTf in diglyme. Li (blue); C (light blue); O (red); S (yellow): F (violet); and H (gray).

preserved even at short interionic distances. However, contrasted to the previous isolated $\mathrm{Li}^{+}$case, the local structures of CIP involve two types of modifications, as shown in the snapshots of Figure 6: for the specific case of DME, one observes the exchange of two of the original ether-O sites by other two "equivalent" ones (composing the $\mathrm{SO}_{3}$ group of the counterion) equally shared in a straddled-like structure of type A. On the other hand, solvation structures of CIP of type B involves the exchange of only one original ether-O site by one of the counterion in a linear-like $\mathrm{S}-\mathrm{O} \cdots \mathrm{Li}^{+}$coordination.

The direct inspection of the relative stabilities of the two structures and the positions of the corresponding local minima in the two solvents, shown in the inset of Figure 4, clearly demonstrate that the effective interionic attraction should be milder in DG than in DME. As such, we are led to conclude that the sources of the observed differences in the extent of ionic association might be ascribed to the details of an intricate balance between ion-ion and ion-solvent interactions that would benefit either one of the two possible contact-ion-pair coordinations, depending of the particular solvent considered. On the other hand, the plots in the right panel of Figure 4 reveal a much less clear stabilization of the above-mentioned solvation structures. This is not unexpected given the wider variety of length scales describing the solvation structure $\mathrm{Li}$ TFSI pairs where, for example, the ion-ion coordination of type $\mathrm{A}$ is articulated via a pair of $\mathrm{O}$-sites, each one located in a different, more distant, $\mathrm{SO}_{2}$ groups.

Rhodes and $\mathrm{Frech}^{48}$ have reported results of Raman spectroscopy for a concentrated $(1.86 \mathrm{M})$ LiTf solution in diglyme, and they proposed that $\mathrm{Li}^{+}$is coordinated by three ether-O sites and one $\mathrm{O}$ from a triflate $\mathrm{SO}_{3}$ group, as a part of a CIP. That structure could be reconciliated with the one of type B shown in Figure 6 if we consider that at high salt concentrations, the counteranion can get closer to the $\mathrm{Li}^{+}$ ion, displacing the second diglyme molecule coordinated to the cation. On the other hand, Brouillette et al. ${ }^{49}$ studied the Raman spectra of LiTFSI in DME and diglyme in different concentrations and concluded that in both solvents, SSIP are formed at low concentrations, which is in agreement with the structure found in our MD simulations.

In summary, the MD simulations qualitatively reproduce the ionic association trends and structure of the CIP observed experimentally. Differences in $K_{A}$, especially for the case of LiTf in both solvents, are probably determined by a delicate balance between ion/ion and ion/solvent couplings. Such $K_{\mathrm{A}}$ differences, as discussed in Section 2.2, allow us to explain the order of conductivities observed in finite-concentration solutions, provided the differences in solvent viscosities are also considered.

2.4. Ionic Diffusion of Lithium from Conductivity Data and MD Simulations. To compare the ionic diffusion coefficients obtained by MD simulations with the ionic limiting molar conductivities reported in Table 1 , we resorted to the Nernst-Einstein relationship ${ }^{50}$

$$
D_{\mathrm{i}}^{0}=\frac{k T}{z e} \lambda_{\mathrm{i}}^{0}
$$

which is valid at infinite dilution. The infinite-dilution diffusion coefficients, $D_{\mathrm{i}}^{0}$, obtained from eq 3 are listed in Table 3 .

Table 3. Ionic Diffusion Coefficients $\left(10^{-6} \mathrm{~cm}^{2} \mathrm{~s}^{-1}\right)$ in DME and Diglyme at $298.15 \mathrm{~K}$

\begin{tabular}{lcccccc}
\multicolumn{1}{c}{ ion } & $D_{\mathrm{i}, \mathrm{DME}}^{0}$ & $D_{\mathrm{i}, \mathrm{DG}}^{0}$ & $D_{\mathrm{i}, \mathrm{DME}}^{\mathrm{MD}}$ & $D_{\mathrm{i}, \mathrm{DG}}^{\mathrm{MD}}$ & $D_{\mathrm{i}, \mathrm{DM}}^{\mathrm{MD}}$ & $D_{\mathrm{i}, \mathrm{DG}}^{\mathrm{MD}}$ \\
$\mathrm{Li}^{+}$ & 13.6 & 5.6 & 8.3 & 1.8 & 12.3 & 4.5 \\
$\mathrm{Tf}^{-}$ & 21.0 & 9.8 & 7.7 & 1.5 & & \\
$\mathrm{TFSI}^{-}$ & 19.2 & 9.0 & 6.3 & 1.9 & & \\
\hline
\end{tabular}

In all the cases, diffusion in DME is approximately a factor 2 faster than the one observed in diglyme, which is somehow expected, taking into account the difference in viscosities between DME and diglyme (see Table S2 in the Supporting Information) and the well-known $\eta^{-1}$ dependence of $D$ derived from the Stokes-Einstein relationship. ${ }^{51}$

The MD simulation results for the ionic diffusion coefficients, $D_{\mathrm{i}}^{\mathrm{MD}}$, are listed in the fourth and fifth columns of Table 3. One can observe that the experimental trends for a particular tagged ion in both solvents are reproduced by the simulation results, i.e., ionic diffusion in DME is faster than that in diglyme. However, whereas the agreements for the $\mathrm{Li}^{+}$ results are still acceptable, simulation results for the diffusion of the anionic species fall too low when compared to the ones obtained from the conductivity data. Moreover, note that, invoking the above-mentioned Stokes-Einstein relationship, one can even improve the accordance between the experimental and the simulated results for $\mathrm{Li}^{+}$by simply rescaling the raw data of the simulations by the corresponding ratio between the experimental and the simulated solvent viscosities, namely

$$
D_{\mathrm{i}}^{\mathrm{MD} *}=D_{\mathrm{i}}^{\mathrm{MD}} \frac{\eta^{\mathrm{MD}}}{\eta^{\exp }}
$$

The rescaled $\mathrm{Li}^{+}$ionic diffusion coefficients, $\mathrm{D}_{\mathrm{i}}^{\mathrm{MD} *}$, obtained using the ratio between the experimental viscosities of the 
solvents (see the Supporting Information) and the calculated ones by using $\mathrm{MD}$ simulations ${ }^{52}$ are also displayed in last two columns of Table 3. One can observe that now, the differences between the simulation and the experimental results for the $\mathrm{Li}^{+}$ diffusion constants are comparable, within a $20 \%$ discrepancy.

An alternative strategy would be to rescale the ion charges, but considering that the $\mathrm{Li}^{+}$ion diffuses to maintain a practically unchanged, tightly bound, spherical-like solvation shell, it is expected that its infinite-dilution diffusion coefficient depends more on the solvent-solvent interaction, that is, on the viscosity rather than the ion charge scaling. Because the interactions of the bulky anions with the solvent are weaker, making the solvation structure not so persistent, the viscosity correction would be less reasonable than in the case of $\mathrm{Li}^{+}$ion, so it was not performed.

Rescaling the charges of anions will probably result in MD infinite-dilution diffusion coefficients closer to the experimental values. Such parametrization improvements to describe dynamical properties will surely deserve further analysis, but they are beyond the scope of the present work.

Before closing this section, it is worth mentioning that the transport coefficients reported in this work for $\mathrm{Li}^{+}, \mathrm{Tf}^{-}$, and $\mathrm{TFSI}^{-}$ions cannot be directly compared with those determined by MD simulations ${ }^{45}$ for LiTFSI in DME, or experimentally by pulse-gradient spin-echo ${ }^{7} \mathrm{Li}$ and ${ }^{19} \mathrm{~F} \mathrm{NMR}{ }^{53}$ for LiTFSI in DME and diglyme because the diffusion coefficients reported in those works correspond to concentrated solutions (glyme/salt ratio equal to 20). However, the experimental diffusion coefficients obtained by $\mathrm{NMR}$ for $\mathrm{Li}^{+}$ and $\mathrm{TFSI}^{-}$exhibit the same trend as our infinite-diffusion data, that is, $D_{\mathrm{TFSI}^{-} / \mathrm{DME}}>D_{\mathrm{Li}^{+} / \mathrm{DME}}>D_{\mathrm{TFSI}^{-} / \mathrm{DG}}>D_{\mathrm{Li}^{+} / \mathrm{DG}}$.

\section{CONCLUSIONS}

The electrical conductivities of LiTf and LiTFSI in DME and diglyme were measured at $298.15 \mathrm{~K}$ over a wide range of concentrations, including the triple-ion-formation region, which determines the minimum in the molar conductivity as a function of concentration.

The formation constant of ion pairs $\left(K_{\mathrm{A}}\right)$ was determined using the Fuoss-Kraus and the FHFP treatment by fixing the infinite-dilution molar conductivities of the corresponding salts from the fractional Walden rule for the corresponding ions. Both treatments yield consistent results, and the FK equation allowed us to obtain reliable values for the formation constant of triplet ions $\left(K_{\mathrm{T}}\right)$. Following the idea that strong association promote large $\mathrm{Li}_{2} \mathrm{O}_{2}$ discharge deposits through a top-down mechanism, ${ }^{23}$ the system LiTf/DME would be the best choice as the electrolyte for a LAB.

The speciation obtained for the LiTf/diglyme system was compared with those reported in previous studies by implementing different approaches, and it is concluded that the results obtained through the conductivity analysis using the equations for highly associated electrolytes yield a consistent association scheme. By comparing the association constants and conductivities of the four systems studied, we found that a lower conductivity in concentrated solutions is not an absolute criteria for a stronger association because the solvent viscosity determines the conductivity in the concentrated region, whereas dielectric constant and specific ion-solvent interactions determine the association degree.

Our measurements in DME and diglyme solvents expand the data for LiTf and LiTFSI in solvents of low dielectric constant $(\varepsilon<10)$. The trend is consistent with an increase in
$K_{\mathrm{A}}$ with increasing $1 / \varepsilon$, but important differences are observed for the association constants of LiTf and, to a lesser extent, for LiTFSI in DME and diglyme. The MD simulations allowed us to rationalize these differences in terms of the competing interactions of the $\mathrm{O}$-sites of the ethers and the $\mathrm{SO}_{x}$ groups of the corresponding anions with $\mathrm{Li}^{+}$ion.

The limiting $\mathrm{Li}^{+}$diffusivity derived from the fractional Walden rule agrees quite well with those obtained from MD simulations, provided the difference between the experimental solvent viscosity and the calculated one using MD is accounted for. This is not the case for the anions diffusivities probably as a consequence of deficiencies in the treatment of cross solutesolvent interactions adopted in this work.

\section{EXPERIMENTAL AND COMPUTATIONAL PROCEDURES}

4.1. Materials. Anhydrous bis(2-methoxy-ethyl)ether (diglyme or DG, Sigma-Aldrich, $99.5 \%$ pure) and 1,2dimethoxyethane (DME, Sigma-Aldrich, 99.5\% pure) were used as received. Lithium trifluoromethanesulfonate $((\mathrm{Li}$ triflate, or LiTf), Sigma-Aldrich, 99.99\%) and lithium bis(trifluoromethanesulfonyl) (LiTFSI, Sigma-Aldrich, 99.95\%) were dried by heating at $140{ }^{\circ} \mathrm{C}$ under vacuum for more than $12 \mathrm{~h}$. All the chemicals were stored in an argon-filled MBRAUN glovebox with oxygen content lower than 0.1 ppm and water content below $2 \mathrm{ppm}$. All the solutions were prepared inside the glovebox and the water content was measured using the Karl Fisher coulometric titration (831 KFCoulometer, Metrohm). The water content of all the solutions studied in this work was less than $50 \mathrm{ppm}$ at the beginning and less than $75 \mathrm{ppm}$ at the end of the conductivity measurements.

4.2. Conductivity Measurements. Two air-tight conductivity cells with platinized platinum electrodes were used to determine the conductivities of LiTf and LiTFSI in DME and diglyme. The cell used for the diluted and moderate concentrations $\left(10^{-5}\right.$ to $\left.0.1 \mathrm{M}\right)$ had a mixing bulb with a magnetic stirrer and a septum to inject an aliquot of stock solution under dry conditions. A capillary cell, with a much larger constant, was used for highly concentrated solutions $(0.5-2 \mathrm{M})$. Both cells were calibrated using standard $\mathrm{KCl}$ aqueous solutions of known specific conductivity ${ }^{54}$ with different concentrations (between 0.01 and $1 \mathrm{~m}$ ) to cover the different ranges of concentrations for each cell. The measured cell constants were $k_{\text {cell1 }}=0.1157 \pm 0.0002 \mathrm{~cm}^{-1}$ for the conventional cell and $k_{\text {cell2 }}=136.9 \pm 0.2 \mathrm{~cm}^{-1}$ for the capillary cell.

For the dilute and moderate range of concentrations, the measurements were performed according to the following protocol. A concentrated stock solution of the salt in the corresponding solvent was prepared inside a glovebox and kept in an air-tight vessel provided with a septum. The conductivity cell was filled with a weighed amount of pure solvent inside the glovebox and then transferred to an oil bath thermostatized at $298.15 \pm 0.05 \mathrm{~K}$. After reaching thermal equilibrium, the electrical resistance of the pure solvent, $R_{\mathrm{sv}}$, was measured. Then, increasing amounts of stock solution were added to the cell using a syringe. The solution was homogenized by magnetic stirring and the solution's electrical resistance, $R_{\mathrm{sc}}$ was determined.

For the concentrated region, each individual solution was prepared using a volumetric flask. The capillary cell was filled with the solution inside the glovebox and then transferred to 
the thermostatized oil bath, where the solution's electrical resistance was determined.

For resistance measurements, a LCR meter (GwINSTEK) was used. An alternating current voltage $(100 \mathrm{mV})$ was applied to the electrodes at different frequencies and the resistive and capacitive components were recorded, considering an equivalent resistance-capacitance parallel circuit. The resistance component was recorded at five frequencies between 0.5 and 5 $\mathrm{kHz}$ and the extrapolated value at infinite frequency was taken as the true value used in the calculations.

The specific conductivity, $\kappa$, and the molar conductivity, $\Lambda$, of the electrolyte were determined according to

$$
\Lambda=\frac{\kappa}{c}=\frac{k_{\text {cell }}}{c}\left(\frac{1}{R_{\mathrm{sc}}}-\frac{1}{R_{\mathrm{sv}}}\right)
$$

where $c$ is the electrolyte molar concentration, $R_{\mathrm{sc}}$ is the solution resistance and $R_{\mathrm{sv}}$ is the solvent resistance. The solvent resistance correction is small in the concentrated region, but becomes important in the very dilute region, being the main source of error.

4.3. Molecular Dynamic Simulations. We performed MD simulations on systems composed of $N_{s}$ solvent molecules (DME and DG) and isolated ion pairs, confined within fully periodic, cubic boxes. Concerning the ion pairs, we considered those combining $\mathrm{Li}^{+}$as cation and $\mathrm{Tf}^{-}$or $\mathrm{TFSI}^{-}$as anions. In all the cases, the total number of solvent molecules were set to $N_{\mathrm{s}}=500$; the linear dimensions of the simulation boxes were adjusted at values close to $4.5-5.0 \mathrm{~nm}$, so as to bring the global densities in agreement with the corresponding experimental values: $\rho_{\mathrm{DME}}=0.869 \mathrm{~g} \mathrm{~cm}^{-3}$ and $\rho_{\mathrm{DG}}=0.937 \mathrm{~g} \mathrm{~cm}^{-3}$ at 298.15 K.

All the molecules were modeled as fully flexible collections of atoms. For ethers, we implemented the parametrization reported by Barbosa et al. ${ }^{52}$ For ionic species, we adopted the parameters already reported. ${ }^{55,56}$ The potential energy of the system was considered as a sum of pair-decomposable site-site terms. The intramolecular interactions comprised of standard stretching, bending, and dihedral contributions, whereas intermolecular interactions combined dispersion (LennardJones) and Coulomb terms. To evaluate cross-interactions, we implemented the usual arithmetic and geometrical means for the length and energy parameters describing the dispersive Lennard-Jones interactions. Forces derived from the latter contributions were computed using a cutoff distance set at 1.3 $\mathrm{nm}$, whereas the Ewald sum methods were applied to treat the long-range nature of Coulomb interactions.

Appropriate sampling of equilibrium properties was collected along canonical runs with the thermostats set at $T$ $=298.15 \mathrm{~K}$, lasting typically $10 \mathrm{~ns}$; dynamical properties were computed as averages obtained from five statistically independent microcanonical runs, each one lasting $5 \mathrm{~ns}$. All simulations were performed using the NAMD package. ${ }^{57}$

The potential of mean forces was computed using the $A B F$ procedure. $^{58-60}$ The scheme relies on the generation of trajectories along a chosen reaction coordinate, $\xi$, experiencing practically no free energy barriers. This is achieved by means of biasing forces estimated along a series of small bins, which, in turn, span the complete $\xi$ interval. These forces are applied to flatten the free energy surface, so that $\xi$ becomes uniformly sampled. In this case, $\xi$ was taken as the distance between $\mathrm{Li}^{+}$ and the $S(N)$ site in the anion.
The spatial correlations between $\mathrm{Li}^{+}$and the solvent were analyzed by computing the pair correlation functions $g_{\mathrm{Li}, \mathrm{X}}$ between the cation and a tagged solvent site $\mathrm{X}$, namely

$$
g_{\mathrm{Li}^{+}, \mathrm{X}}(r)=\frac{1}{4 \pi r^{2} \rho_{\mathrm{X}}} \sum_{i=1}^{N_{\mathrm{S}}}\left\langle\delta\left(\left|r_{\mathrm{Li}^{+}}-r_{i}^{\mathrm{X}}\right|-r\right)\right\rangle
$$

where $r_{\mathrm{Li}}{ }^{+}$and $r_{i}^{\mathrm{X}}$ correspond to the positions of the cation and the $\mathrm{X}$-site $(\mathrm{X}=\mathrm{O}$, methylene $\mathrm{C}$, and methyl $\mathrm{C})$ in the ether chains, respectively; $\rho_{\mathrm{X}}$ represents the corresponding bulk density of $\mathrm{X}$-sites and $\langle\ldots\rangle$ denotes an equilibrium ensemble average.

Diffusion coefficients were computed from the long-time, limiting behavior of the corresponding mean square displacements, namely

$$
D_{\alpha}=\lim _{t \rightarrow \infty} \frac{1}{6 t}\left\langle\left|r_{\alpha}(t)-r_{\alpha}(0)\right|^{2}\right\rangle
$$

where $r_{\alpha}(t)$ represents the position of the $\alpha$ particle at time $t$.

\section{ASSOCIATED CONTENT}

\section{S Supporting Information}

The Supporting Information is available free of charge on the ACS Publications website at DOI: 10.1021/acsomega.8b01443.

Concentration dependence of the molar conductivity in highly associated electrolytes, estimation of the ionic infinite-dilution molar conductivities, experimental electrical molar conductivities, viscosity and relative dielectric constant of the glymes, ionic molar conductivities of the ions $\mathrm{Li}^{+}, \mathrm{Tf}^{-}$, and $\mathrm{TFSI}^{-}$, and association constant of lithium salts in aprotic solvents (PDF)

\section{AUTHOR INFORMATION}

\section{Corresponding Authors}

*E-mail: dlariag@gmail.com (D.L.).

*E-mail: hrcorti@tandar.cnea.gov.ar (H.R.C.).

ORCID 1

Horacio R. Corti: 0000-0003-4718-5236

\section{Author Contributions}

The manuscript was written through contributions of all the authors. All the authors have given approval to the final version of the manuscript.

\section{Notes}

The authors declare no competing financial interest.

\section{ACKNOWLEDGMENTS}

The authors thank financial support from Agencia Nacional de Promoción Científica y Tecnológica (PICT 2013-1818), CNEA, and CONICET (PIP 112-20130100808 and PIP 112-20110100464). J.R., D.L., and H.R.C. are permanent research fellows of CONICET. G.H. and M.F. thank CONICET for doctoral and postdoctoral fellowships, respectively.

\section{ABBREVIATIONS}

$\mathrm{ABF}$, adaptive biasing force; CIP, contact-ion pair; DG, diethylene glycol dimethyl ether or diglyme; DME, 1,2dimethoxyethane; DMSO, dimethyl sulfoxide; DN, donor number; FHFP, Fuoss-Hsia-Fernández-Prini; FK, Fuoss- 
Kraus; LAB, lithium-air battery; LiTf, lithium trifluoromethanesulfonate; LiTFSI, lithium bis(trifluoromethanesulfonyl)imide; MD, molecular dynamics; ORR, oxygen reduction reaction; SSIP, solvent-separated ion pair; TEGDME, tetraethylene glycol dimethyl ether

\section{REFERENCES}

(1) Bruce, P. G.; Freunberger, S. A.; Hardwick, L. J.; Tarascon, J.-M. $\mathrm{Li}-\mathrm{O}_{2}$ and Li-S batteries with high energy storage. Nat. Mater. 2012, $11,19-29$.

(2) Girishkumar, G.; McCloskey, B.; Lunz, A. C.; Swanson, S.; Wilcke, W. Lithium-air battery: Promise and challenges. J. Phys. Chem. Lett. 2010, 1, 2193-2203.

(3) Husch, T.; Korth, M. Charting the known chemical space for non-aqueous lithium-air battery electrolyte solvents. Phys. Chem. Chem. Phys. 2015, 17, 22596-22603.

(4) Lee, S.-Y.; Ueno, K.; Angell, C. A. Lithium salt solutions in mixed sulfone and sulfone-carbonate solvents: A Walden plot analysis of the maximally conductive compositions. J. Phys. Chem. C 2012, 116, 23915-23920.

(5) Abraham, K. M.; Jiang, Z. A polymer electrolyte-based rechargeable lithium/oxygen battery. J. Electrochem. Soc. 1996, 143, $1-5$.

(6) Débart, A.; Paterson, A. J.; Bao, J.; Bruce, P. G. $\alpha-\mathrm{MnO}_{2}$ nanowires: A catalyst for the $\mathrm{O}_{2}$ electrode in rechargeable lithium batteries. Angew. Chem. 2008, 120, 4597-4600.

(7) Albertus, P.; Girishkumar, G.; McCloskey, B.; Sánchez-Carrera, R. S.; Kozinsky, B.; Christensen, J.; Luntz, A. C. Identifying capacity limitations in the Li/oxygen battery using experiments and modeling batteries and energy storage. J. Electrochem. Soc. 2011, 158, A343A351.

(8) Bryantsev, V. S.; Blanco, M. Computational study of the mechanisms of superoxide-induced decomposition of organic carbonate-based electrolytes. J. Phys. Chem. Lett. 2011, 2, 379-383.

(9) Freunberger, S. A.; Chen, Y.; Peng, Z.; Griffin, J. M.; Hardwick, L. J.; Bardé, F.; Novák, P.; Bruce, P. G. Reactions in the rechargeable lithium $-\mathrm{O}_{2}$ battery with alkyl carbonate electrolytes. J. Am. Chem. Soc. 2011, 133, 8040-8047.

(10) McCloskey, B. D.; Bethune, D. S.; Shelby, R. M.; Girishkumar, G.; Luntz, A. C. Solvents' critical role in nonaqueous lithium-oxygen battery electrochemistry. J. Phys. Chem. Lett. 2011, 2, 1161-1166.

(11) Laoire, C. O.; Mukerjee, S.; Abraham, K. M.; Plichta, E. J.; Hendrickson, M. A. Influence of nonaqueous solvents on the electrochemistry of oxygen in the rechargeable lithium-air battery. J. Phys. Chem. C 2010, 114, 9178-9186.

(12) Johnson, L.; Li, C.; Liu, Z.; Chen, Y.; Freunberger, S. A.; Tarascon, J.-M.; Ashok, P. C.; Praveen, B. B.; Dholakia, K.; Bruce, P. G. The role of $\mathrm{LiO}_{2}$ solubility in $\mathrm{O}_{2}$ reduction in aprotic solvents and its consequences for $\mathrm{Li}-\mathrm{O}_{2}$ batteries. Nat. Chem. 2014, 6, 10911099.

(13) Peng, Z.; Freunberger, S. A.; Chen, Y.; Bruce, P. G. A reversible and higher-rate $\mathrm{Li}^{-} \mathrm{O}_{2}$ battery. Science 2012, 337, 563-566.

(14) McCloskey, B. D.; Valery, A.; Luntz, A. C.; Gowda, S. R.; Wallraff, G. M.; Garcia, J. M.; Mori, T.; Krupp, L. E. Combining accurate $\mathrm{O}_{2}$ and $\mathrm{Li}_{2} \mathrm{O}_{2}$ assays to separate discharge and charge stability limitations in nonaqueous $\mathrm{Li}-\mathrm{O}_{2}$ batteries. J. Phys. Chem. Lett. 2013, 4, 2989-2993.

(15) Sharon, D.; Afri, M.; Noked, M.; Garsuch, A.; Frimer, A. A.; Aurbach, D. Oxidation of dimethyl sulfoxide solutions by electrochemical reduction of oxygen. J. Phys. Chem. Lett. 2013, 4, 31153119.

(16) Kwabi, D. G.; Batcho, T. P.; Amanchukwu, C. V.; OrtizVitoriano, N.; Hammond, P.; Thompson, C. V.; Shao-Horn, Y. Chemical instability of dimethyl sulfoxide in lithium-air batteries. J. Phys. Chem. Lett. 2014, 5, 2850-2856.

(17) Freunberger, S. A.; Chen, Y.; Drewett, N. E.; Hardwick, L. J.; Bardé, F.; Bruce, P. G. The lithium-oxygen battery with ether-based electrolytes. Angew. Chem., Int. Ed. 2011, 50, 8609-8613.
(18) Laoire, C. O.; Mukerjee, S.; Plichta, E. J.; Hendrickson, M. A.; Abraham, K. M. Rechargeable lithium/TEGDME- $\mathrm{LiPF}_{6} / \mathrm{O}_{2}$ battery. J. Electrochem. Soc. 2011, 158, A302-A308.

(19) Bryantsev, V. S.; Giordani, B.; Wlaker, W.; Blanco, M.; Zecevic, S.; Sasaki, K.; Uddin, J.; Addison, D.; Chase, J. V. Predicting solvent stability in aprotic electrolyte $\mathrm{Li}-$ air batteries: Nucleophilic substitution by the superoxide anion radical $\left(\mathrm{O}_{2}{ }^{-}\right)$. J. Phys. Chem. A 2011, 115, 12399-12409.

(20) Schwenke, K. U.; Meini, S.; Wu, X.; Gasteiger, H. A.; Piana, M. Stability of superoxide radicals in glyme solvents for non-aqueous $\mathrm{Li}$ O2 battery electrolytes. Phys. Chem. Chem. Phys. 2013, 15, 1183011839.

(21) Tamura, T.; Yoshida, K.; Hachida, T.; Tsichiya, M.; Nakamura, M.; Kazue, Y.; Tachikawa, N.; Dokko, K.; Watanabe, M. Physicochemical properties of glyme- $\mathrm{Li}$ salt complexes as a new family of room-temperature ionic liquids. Chem. Lett. 2010, 39, 753755 .

(22) Du, P.; Lu, J.; Lau, K. C.; Luo, X.; Bareño, J.; Zhang, X.; Ren, Y.; Zhang, Z.; Curtiss, L. A.; Sune, Y.-K.; Amine, K. Compatibility of lithium salts with solvent of the non-aqueous electrolyte in $\mathrm{Li}-$ $\mathrm{O}_{2}$ batteries. Phys. Chem. Chem. Phys. 2013, 15, 5572-5581.

(23) Sharon, D.; Hirsberg, D.; Salama, M.; Afri, M.; Frimer, A. A.; Noked, M.; Kwak, W.; Sun, Y.-K.; Aurbach, D. Mechanistic role of $\mathrm{Li}^{+}$ dissociation level in aprotic $\mathrm{Li}-\mathrm{O}_{2}$ battery. ACS Appl. Mater. Interfaces 2016, 8, 5300-5307.

(24) Burke, C. M.; Pande, V.; Khetan, A.; Viswanathan, V.; McCloskey, B. D. Enhancing electrochemical intermediate solvation through electrolyte anion selection to increase nonaqueous $\mathrm{Li}$ $\mathrm{O}_{2}$ battery capacity. Proc. Natl. Acad. Sci. U.S.A. 2015, 112, 92939298.

(25) Khetan, A.; Arjmandi, H. R.; Pande, V.; Pitsch, H.; Viswanathan, V. Understanding ion pairing in high-salt concentration electrolytes using classical molecular dynamics simulations and its implications for nonaqueous $\mathrm{Li}-\mathrm{O}_{2}$ batteries. J. Phys. Chem. C 2018, $122,8094-8101$.

(26) Petrowsky, M.; Frech, R.; Suarez, S. N.; Jayakody, J. R. P.; Greenbaum, S. Investigation of fundamental transport properties and thermodynamics in diglyme-salt solutions. J. Phys. Chem. B 2006, 110, 23012-23021.

(27) Brouillette, D.; Perron, G.; Desnoyers, J. E. Apparent molar volume, heat capacity, and conductance of lithium bis(trifluoromethylsulfone) imide in glymes and other aprotic solvents. J. Solution Chem. 1998, 27, 151-182.

(28) Fuoss, R. M.; Kraus, C. A. Properties of electrolytic solutions. IV. The conductance minimum and the formation of triple ions due to the action of coulomb forces. J. Am. Chem. Soc. 1933, 55, 23872399.

(29) Barthel, J.; Gerber, R.; Gores, H. J. The temperature dependence of the properties of electrolyte solutions. VI. Triple ion formation in solvents of low permittivity exemplified by $\mathrm{LiBF}_{4}$ solutions in dimethoxyethane. Ber. Bunsenges. Phys. Chem. 1984, 88, $616-622$.

(30) Laría, D.; Corti, H. R.; Fernández Prini, R. The cluster theory for electrolyte solutions: its extension and its limitations. J. Chem. Soc., Faraday Trans. 1990, 86, 1051-1056.

(31) Okan, S. E.; Champeney, D. C. Molar conductance of aqueous solutions of sodium, potassium, and nickel trifluoromethanesulfonate at $25{ }^{\circ} \mathrm{C}$. J. Solution Chem. 1997, 26, 405-414.

(32) Fuoss, R. M.; Kraus, C. A. Properties of electrolytic solutions. IV. The conductance minimum and the formation of triple ions due to the action of coulomb forces. J. Am. Chem. Soc. 1933, 55, 23872399.

(33) Fuoss, R. M.; Hsia, K. L. Association of 1-1 salts in water. Proc. Natl. Acad. Sci. U.S.A. 1967, 57, 1550-1557.

(34) Fernández-Prini, R. Conductance of electrolyte solutions. A modified expression for its concentration dependence. Trans. Faraday Soc. 1969, 65, 3311-3315.

(35) Salomon, M.; Uchiyama, M. C. Treatment of triple ion formation. J. Solution Chem. 1987, 16, 21-30. 
(36) Longinotti, M. P.; Corti, H. R. Fractional Walden rule for electrolytes in supercooled disaccharide aqueous solutions. J. Phys. Chem. B 2009, 113, 5500-5507.

(37) Boileau, S.; Hemery, P. Conductance of some tetraphenylboron and fluorenyl salts in tetrahydropyran. Electrochim. Acta 1976, 21, 647-655.

(38) Claude-Montigny, B.; Rioteau, E.; Lemordant, D.; Topart, P.; Bosser, G. Theory of ionic conduction in organic solvents and gel electrolytes: application to the system $\mathrm{DG} / \mathrm{LiCF}_{3} \mathrm{SO}_{3}$ and diacrylate/ DG/LiCF $\mathrm{SO}_{3}$. Electrochim. Acta 2001, 47, 533-541.

(39) Plewa, A.; Kalita, M.; Siekierski, M. Estimation of ion pair formation in mixtures of glymes and 1,4-dioxane. Electrochim. Acta 2007, 53, 1527-1534.

(40) Plewa-Marczewska, A.; Kalita, M.; Marczewski, M.; Siekierski, M. NMR studies of equilibrium in electrolytes. Ionic pairing in glymes. Electrochim. Acta 2010, 55, 1389-1395.

(41) Prue, J. E. Ion pairs and complexes: free energies, enthalpies, and entropies. J. Chem. Educ. 1969, 46, 12-16.

(42) Dhumal, N. R.; Gejii, S. P. Theoretical studies on blue versus red shifts in diglyme- $\mathrm{M}^{+}-\mathrm{X}^{-}\left(\mathrm{M}=\mathrm{Li}, \mathrm{Na}\right.$, and $\mathrm{K}$ and $\mathrm{X}=\mathrm{CF}_{3} \mathrm{SO}_{3}$, $\mathrm{PF}_{6}$, and $\left.\left.\left(\mathrm{CF}_{3} \mathrm{SO}_{2}\right)_{2} \mathrm{~N}\right)\right)$. J. Phys. Chem. A 2006, 110, 219-227.

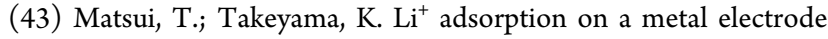
from glymes. Electrochim. Acta 1998, 43, 1355-1360.

(44) Kwabi, D. G.; Bryantsev, V. S.; Batcho, T. P.; Itkis, D. M.; Thompson, C.-V.; Shao-Horn, Y. Experimental and computational analysis of the solvent-dependent $\mathrm{O}_{2} / \mathrm{Li}^{+}-\mathrm{O}_{2}{ }^{-}$redox couple: Standard potentials, coupling strength, and implications for lithium-oxygen batteries. Angew. Chem., Int. Ed. 2016, 55, 3129-3134.

(45) Callsen, M.; Sodeyama, K.; Fureta, K.; Tateyama, Y.; Hamada, I. The solvation structure of lithium ions in an ether based electrolyte solution from first-principles molecular dynamics. J. Phys. Chem. B 2017, 121, 180-188.

(46) Shinoda, W.; Hatanaka, Y.; Hirakawa, M.; Okazaki, S.; Tsuziki, S.; Ueno, K.; Watanabe, M. Molecular dynamics study of thermodynamic stability and dynamics of $[\mathrm{Li}(\mathrm{glyme})]^{+}$complex in lithium-glyme solvate ionic liquids. J. Chem. Phys. 2018, 148, No. 193809.

(47) Park, C.; Kanduč, M.; Chudoba, R.; Ronneburg, A.; Risse, S.; Ballauf, M.; Dzubiella, J. Molecular simulations of electrolyte structure and dynamics in lithium-sulfur battery solvents. J. Power Sources 2018, 373, 70-78.

(48) Rhodes, C. P.; Frech, R. Local structure in crystalline and amorphous phases of diglyme- $\mathrm{LiCF}_{3} \mathrm{SO}_{3}$ and poly(ethylene oxide)$\mathrm{LiCF}_{3} \mathrm{SO}_{3}$ systems: Implications for the mechanism of ionic transport. Macromolecules 2001, 34, 2660-2666.

(49) Brouillette, D.; Irish, D. E.; Taylor, N. J.; Perron, G.; Odziemkowski, M.; Desnoyers, J. E. Stable solvates in solution of lithium bis(trifluoromethylsulfonate)imide in glymes and other aprotic solvents: Phase diagrams, crystallography and Raman spectroscopy. Phys. Chem. Chem. Phys. 2002, 4, 6063-6071.

(50) Cussler, E. L. Diffusion: Mass Transfer in Fluid Systems, 2nd ed.; Cambridge University Press, 1997.

(51) Haase, R. Thermodynamics of Irreversible Processes; Dover: New York, 1963.

(52) Barbosa, N. S. V.; Zhang, Y.; Lima, E. R. A.; Tavares, F. W.; Maginn, E. J. Development of an AMBER-compatible transferable force field for poly(ethylene glycol)ethers (glymes). J. Mol. Model. 2017, 23, 194.

(53) Hayamizu, K.; Aihara, Y.; Arai, S.; García Martínez, C. Pulsegradient spin-echo ${ }^{1} \mathrm{H},{ }^{7} \mathrm{Li}$, and ${ }^{19} \mathrm{~F}$ NMR diffusion and ionic conductivity measurements of 14 organic electrolytes containing $\mathrm{LiN}\left(\mathrm{SO}_{2} \mathrm{CF}_{3}\right)_{2}$. J. Phys. Chem. B 1999, 103, 519-524.

(54) Barthel, J.; Feuerlein, F.; Neueder, R.; Wachter, R. Calibration of conductance cells at various temperatures. J. Solution Chem. 1980, 9, 209-219.

(55) Horinek, D.; Mamatkulov, S. I.; Netz, R. R. Rational design of ion forces fields based on thermodynamic solvation properties. J. Chem. Phys. 2009, 130, No. 124507.
(56) Lopes, J. N. C.; Pádua, A. A. H. Molecular force field for ionic liquids composed of triflate or bistriflimide anion. J. Phys. Chem. B 2004, 108, 16893-16898.

(57) Phillips, J. C.; Braun, R.; Wang, W.; Gumbart, J.; Tajkhorshid, E.; Villa, E.; Chipot, C.; Skeel, R. D.; Kale, L.; Schulten, K. Scalable molecular dynamics with NAMD. J. Comput. Chem. 2005, 26, 17811802.

(58) Darve, E.; Pohorille, A. J. Calculating free energies using average force. J. Chem. Phys. 2001, 115, 9169-9183.

(59) Hénin, J.; Chipot, C. J. Overcoming free energy barriers using unconstrained molecular dynamics simulations. J. Chem. Phys. 2004, $121,2904-2914$.

(60) Rodriguez-Gomez, D.; Darve, E.; Pohorille, A. J. Assessing the efficiency of free energy calculation methods. J. Chem. Phys. 2004, $120,3563-3578$. 